\title{
The Nature of Bonding of Hyperlithiated Molecules Beyond the Octet Rule
}

\author{
Hiroshi Kudo* \\ Department of Chemistry, Graduate School of Science, Tohoku University, Sendai 980-8578, Japan
}

\author{
Received: November 2, 2001
}

Following an overview on the nature of bonding of such hypervalent molecules as $\mathrm{Li}_{n} \mathrm{~A}\left(\mathrm{Li}_{6} \mathrm{C}, \mathrm{Li}_{3} \mathrm{O}, \mathrm{Li}_{4} \mathrm{O}, \mathrm{Li}_{3} \mathrm{~S}\right.$, $\left.\mathrm{Li}_{4} \mathrm{~S}, \mathrm{Li}_{4} \mathrm{P}\right)$ and $\mathrm{M}_{2} \mathrm{CN}(\mathrm{M}=\mathrm{Li}, \mathrm{Na}, \mathrm{K})$, the present paper deals with the molecular and electronic structures of newly found lithium-rich $\mathrm{Li}_{2} \mathrm{~F}$ and $\mathrm{Li}_{2} \mathrm{OH}$ molecules as well as $\mathrm{Li}_{2} \mathrm{~F}_{n-1}(n=3,4)$ and $\mathrm{Li}_{n}(\mathrm{OH})_{n-1}(n=3-5)$ clusters which have been detected in supersonic beams effusing from a laser ablation source. The ionization energies (IEs) determined by photoionization were $3.78 \pm 0.2 \mathrm{eV}$ for $\mathrm{Li}_{2} \mathrm{~F}, 4.32 \pm 0.2 \mathrm{eV}$ for $\mathrm{Li}_{3} \mathrm{~F}_{2}$, and $4.30 \pm 0.2 \mathrm{eV}$ for $\mathrm{Li}_{4} \mathrm{~F}_{3}$. Agreements of these IEs with theoretical ones calculated by ab initio $\mathrm{MO}$ methods support that $\mathrm{Li}_{2} \mathrm{~F}$ is in a hyperlithiated configuration (HLC) in which the excess electron delocalizes over the two lithiums, while $\mathrm{Li}_{3} \mathrm{~F}_{2}$ and $\mathrm{Li}_{4} \mathrm{~F}_{3}$ are in a segregated configuration (SC) comprising ionic and non-ionic lithiums resulting from localization of the excess valence electron. Ionization efficiency curves (IECs) measured for $\mathrm{Li}_{n}(\mathrm{OH})_{n-1}(n=2-5)$ are well reproduced with a simulation involving Franck-Condon factors, and this enabled us to identify the global-minimum structure of these species predicted by theoretical calculations with the DFT method. The IEs determined were $4.053 \pm 0.003 \mathrm{eV}$ for $\mathrm{Li}_{2} \mathrm{OH}$ in $\mathrm{HLC}, 3.687 \pm 0.003 \mathrm{eV}$ for $\mathrm{Li}_{3}(\mathrm{OH})_{2}$ in $\mathrm{HLC}, 4.133 \pm 0.003 \mathrm{eV}$ for $\mathrm{Li}_{3}(\mathrm{OH})_{2}$ in $\mathrm{SC}$, and $3.418 \pm 0.009 \mathrm{eV}$ for $\mathrm{Li}_{4}(\mathrm{OH})_{3}$ in $\mathrm{SC}$, and $3.60 \pm 0.11 \mathrm{eV}$ for $\mathrm{Li}_{5}(\mathrm{OH})_{4}$ in $\mathrm{SC}$. Also, $\mathrm{IE}$ of $\mathrm{Li}_{3} \mathrm{O}$ was determined as $3.59 \pm 0.02 \mathrm{eV}$ from reinvestigation with the photoionization technique. Furthermore, $\mathrm{Li}_{3} \mathrm{O}$ was found to be a floppy molecule sharing both the $D_{3 \mathrm{~h}}$ and $C_{2 \mathrm{v}}$ structures from a precise analysis of the observed IEC taking account of the potential energy surface for both neutral and cationic $\mathrm{Li}_{3} \mathrm{O}$. This is the first experimental evidence for "electronomers" or electronic isomers of $\mathrm{Li}_{3} \mathrm{O}$, which have nearly the same stability but are different in localization of the SOMO. It is eventually stressed that delocalization of the excess valence electron over all of the lithium atoms in a molecule is essential to afford hyperlithiated molecules and that the shape of SOMO or HOMO, which accommodates the excess valence electron or electrons, plays a key role in determining the stability of hyperlithiated molecules.

\section{Introduction}

Comprehensive understanding of the nature of hyperlvalent bonding is a subject of current interest since the discovery of $\mathrm{Li}_{3} \mathrm{O}$ in the equilibrium vapor over $\mathrm{Li}_{2} \mathrm{O}$ crystals at elevated temperatures in 1978 by Kudo, Wu, and Ihle with Knudseneffusion mass spectrometry. ${ }^{1,2}$ This molecule possessing nine valence electrons, at least formally, was found to be stable toward dissociation to the corresponding octet molecule $\mathrm{Li}_{2} \mathrm{O}$. For a molecular system with covalent bonds of light elements, the octet rule states that the most stable molecule is formed when eight electrons are shared in the valence shell., ${ }^{3,4}$ All of the hydrides of elements in the second- and third-row of the periodic table obey the rule. However, replacement of hydrogen atoms by lithium atoms in such hydrides as $\mathrm{CH}_{4}$, $\mathrm{NH}_{3}, \mathrm{H}_{2} \mathrm{O}$, and $\mathrm{H}_{2} \mathrm{~S}$ changes the nature of bonding. In fact, further experiments by our group ${ }^{7-14}$ as well as theoretical work by Schleyer et al. ${ }^{15-27}$ have confirmed the existence of thermodynamically stable polylithiated molecules with nine or more valence electrons; e.g., $\mathrm{Li}_{3} \mathrm{~S}$ and $\mathrm{Li}_{4} \mathrm{P}$ with nine valence electrons and $\mathrm{Li}_{6} \mathrm{C}, \mathrm{Li}_{4} \mathrm{O}$, and $\mathrm{Li}_{4} \mathrm{~S}$ with 10 valence electrons. These molecules possessing excess valence electrons and stability toward dissociation are called "hyperlithiated" or hypervalent molecules. Does the hyperlithiated molecule violate the octet rule?

Extended search for hyperlithiated molecule by Knudseneffusion mass spectrometry gave evidence for another type of hyperlithiated or hypervalent molecules $\mathrm{M}_{2} \mathrm{CN}(\mathrm{M}=\mathrm{Li}, \mathrm{Na}$, $\mathrm{K})$, in which the bonding situation was apparently different

*E-mail: kudoh@mail.cc.tohoku.ac.jp. FAX: +81-22-217-6597. from that of $\mathrm{Li}_{n} \mathrm{~A}$; i.e., $\mathrm{Li}_{6} \mathrm{C}, \mathrm{Li}_{3} \mathrm{O}, \mathrm{Li}_{4} \mathrm{O}, \mathrm{Li}_{3} \mathrm{~S}, \mathrm{Li}_{4} \mathrm{~S}, \mathrm{Li}_{4} \mathrm{P}{ }^{28-32}$ Although Schleyer ${ }^{17}$ predicted the existence of other hyperlithiated molecules like $\mathrm{Li}_{4} \mathrm{~N}, \mathrm{Li}_{5} \mathrm{~N}, \mathrm{Li}_{2} \mathrm{~F}$, and $\mathrm{Li}_{3} \mathrm{~F}$ from his theoretical calculations, it was hard to get fruitful experimental results with Knudsen-effusion mass spectrometry for these species. Recently, however, we have detected hyperlithiated $\mathrm{Li}_{2} \mathrm{~F}$ and $\mathrm{Li}_{2} \mathrm{OH}$ molecules as well as lithium-rich clusters $\mathrm{Li}_{2} \mathrm{~F}_{n-1}(n=3,4)$ and $\mathrm{Li}_{n}(\mathrm{OH})_{n-1}(n=3-6)$ in supersonic beams effusing from a laser ablation source. ${ }^{33-36}$

Investigation of molecular and electronic structures of the $\mathrm{Li}_{n} \mathrm{~F}_{n-1}$ and $\mathrm{Li}_{n}(\mathrm{OH})_{n-1}$ systems with excess valence electrons are interesting from a viewpoint of the metal-insulator transition. Recently, experimental and theoretical studies have extensively been carried out to understand the mechanism of metal-insulator transitions, much attention being paid to transitional electronic characters between metal and ionic crystals in non-stoichiometric clusters. ${ }^{37}$ For non-stoichiometric clusters with excessive metal atoms, segregation into metallic and ionic parts is envisaged. From the measurement of ionization energies (IEs) for $\mathrm{Li}_{n} \mathrm{H}_{m}(n=2-11, m=1-3)$, for instance, Vezin et al. reported structures segregated into metallic $\mathrm{Li}_{n-m}$ and ionic $(\mathrm{LiH})_{m} \cdot{ }^{38}$ Bonacic-Koutecký et al. confirmed the segregation by $a b$ initio MO calculations. ${ }^{39}$ Lievens et al. measured IEs of $\mathrm{Li}_{n} \mathrm{O}(n=2-70)$ as a function of the cluster size $n$, and found distinct steps at $n=10,22$, and $42 .{ }^{40}$ These steps are in agreement with a prediction of the shell model for metallic clusters, assuming that two of the lithium valence electrons localize on the oxygen atom. This indicates that the clusters are segregated into metallic $\mathrm{Li}_{n-2}$ and ionic $\mathrm{Li}_{2} \mathrm{O}$. Other examples of segregation were reported for $\mathrm{Li}_{n} \mathrm{C}(n=2-70),{ }^{41} \mathrm{Li}_{n} \mathrm{H}_{m}{ }^{+}[m=$ $1-6, n \leq 22,(n-m)>3],{ }^{42,43} \mathrm{Cs}_{m} \mathrm{O}_{n}(0<m<n, n=3-14)^{44}$, and $\mathrm{Na}_{n} \mathrm{~F}_{n-1} \cdot{ }^{45-47}$ 
Alkali halide clusters with one excess alkali atom, $\mathbf{M}_{n} \mathrm{X}_{n-1}$, tend to leave the excess electron localize at a specific site..$^{37,46-50}$ The electron localization is one of the important aspects of segregation. The most part of $\mathbf{M}_{n} \mathrm{X}_{n-1}$ clusters is ionically bound (ionic part) in contrast to the metal excessive clusters such as $\mathrm{Li}_{n} \mathrm{O}(n \geq 8)$, where the metallic part prevails. ${ }^{40}$ For instance, Durand et al. revealed the electron-localization in $\mathrm{Na}_{n} \mathrm{~F}_{n-1}(n=2-29)$ clusters based on a one-electron pseudopotential calculation, and reported that the measured IEs reflected faithfully the localization character of the excess electron. ${ }^{49}$

In the present paper, I will first briefly summarize the nature of bonding of such hypervalent molecules as $\mathrm{Li}_{n} \mathrm{~A}\left(\mathrm{Li}_{6} \mathrm{C}, \mathrm{Li}_{3} \mathrm{O}\right.$, $\left.\mathrm{Li}_{4} \mathrm{O}, \mathrm{Li}_{3} \mathrm{~S}, \mathrm{Li}_{4} \mathrm{~S}, \mathrm{Li}_{4} \mathrm{P}\right)$ and $\mathrm{M}_{2} \mathrm{CN}(\mathrm{M}=\mathrm{Li}, \mathrm{Na}, \mathrm{K})$, which were detected in equilibrium vapors over solid or liquid samples by Knudsen-effusion mass spectrometry combined with electron impact ionization. This method has an advantage for determining the dissociation energy of the detected species, although it has some disadvantages for obtaining precise values of IE when we use the electron impact ionization. Next, I will discuss on the molecular and electronic structures of hyperlithiated $\mathrm{Li}_{2} \mathrm{~F}$ and $\mathrm{Li}_{2} \mathrm{OH}$ molecules as well as lithiumrich clusters $\mathrm{Li}_{2} \mathrm{~F}_{n-1}(n=3,4)$ and $\mathrm{Li}_{n}(\mathrm{OH})_{n-1}(n=3-5)$ detected in supersonic beams effusing from a laser ablation source. The experiments were performed by a time-of-flight mass spectrometer in which species in the supersonic beam were ionized with pulses from a dye laser pumped by an Nd:YAG laser. ${ }^{36}$ This sophisticated method is advantageous in determining IEs of these species more accurately. A detailed analysis of ionization efficiency curves (IECs) measured by

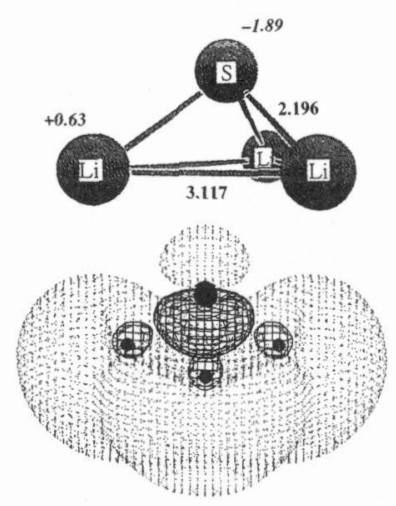

$$
\mathrm{Li}_{3} \mathrm{~S}\left(C_{3 \mathrm{v}}\right)
$$
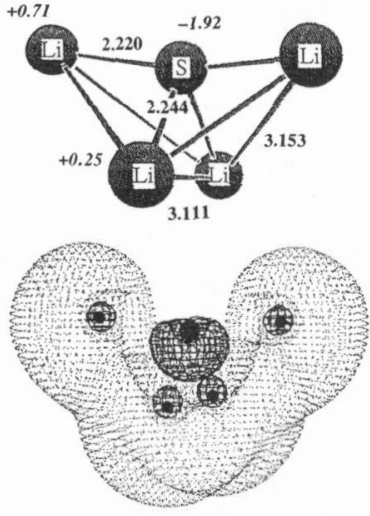

$\mathrm{Li}_{4} \mathrm{~S}\left(C_{2 \mathrm{v}}\right)$
Figure 1. Features of SOMO in $\mathrm{Li}_{3} \mathrm{~S}\left(C_{2 \mathrm{v}}\right)$ and $\mathrm{HOMO}$ in $\mathrm{Li}_{4} \mathrm{~S}\left(C_{2 \mathrm{v}}\right)$ as well as molecular structures deduced from theoretical calculations at UHF/STO-3G level; roman letters are the bond length in $\AA$ and italic letters the natural charge. photoionization enables us to identify the global-minimum structure of the clusters existing in the supersonic beam. Furthermore, I will interpret the molecular and electronic structures of the $\mathrm{Li}_{3} \mathrm{O}$ molecule reinvestigated by an IEC analysis combined with simulations.

\section{2. $\mathrm{Li}_{n} \mathrm{~A}\left(\mathrm{Li}_{6} \mathrm{C}, \mathrm{Li}_{3} \mathrm{O}, \mathrm{Li}_{4} \mathrm{O}, \mathrm{Li}_{3} \mathrm{~S}, \mathrm{Li}_{4} \mathrm{~S}, \mathrm{Li}_{4} \mathrm{P}\right)$ and $\mathrm{M}_{2} \mathrm{CN}(\mathrm{M}=$ $\mathrm{Li}, \mathrm{Na}, \mathrm{K})$ Molecules}

Despite their unusual stoichiometries, the $\mathrm{Li}_{n} \mathrm{~A}$ molecules $\left(\mathrm{Li}_{6} \mathrm{C}, \mathrm{Li}_{3} \mathrm{O}, \mathrm{Li}_{4} \mathrm{O}, \mathrm{Li}_{3} \mathrm{~S}, \mathrm{Li}_{4} \mathrm{~S}\right.$ and $\left.\mathrm{Li}_{4} \mathrm{P}\right)$ are stable toward dissociation to the corresponding octet molecules. ${ }^{1,2,7-14}$ The dissociation energies are summarized in Table 1 . The results of $a b$ initio MO calculations indicate that occupancy of the nine valence electrons in $\mathrm{Li}_{3} \mathrm{~S}$, for instance, is $\left(5 \mathrm{a}_{1}\right)^{2}(3 \mathrm{e})^{4}\left(6 \mathrm{a}_{1}\right)^{2}\left(7 \mathrm{a}_{1}\right)^{1}$ and that of 10 valence electrons in $\operatorname{Li}_{4} S$ is $\left(6 a_{1}\right)^{2}\left(3 b_{1}\right)^{2}\left(7 a_{1}\right)^{2}$ $\left(3 b_{2}\right)^{2}\left(8 a_{1}\right)^{2}$. The highest orbital $\left(7 a_{1}\right)$ of $L_{3} S$ is singly occupied orbital (SOMO) and the $8 \mathrm{a}_{1}$ orbital of $\mathrm{Li}_{4} \mathrm{~S}$ is HOMO. The excess valence electrons accommodate in SOMO or HOMO. Either one and two excess valence electrons in these molecules delocarize over all of the lithium atoms and contribute to the formation of a $\mathrm{Li}_{n}{ }^{m+}$ cage with $\mathrm{Li}-\mathrm{Li}$ bonds Figure 1 depicts the features of $\mathrm{SOMO}$ in $\mathrm{Li}_{3} \mathrm{~S}$ and $\mathrm{HOMO}$ in $\mathrm{Li}_{4} \mathrm{~S}$ deduced from theoretical calculations at the UHF/STO$3 \mathrm{G}$ level. ${ }^{14}$ The SOMO of $\mathrm{Li}_{3} \mathrm{~S}$ seems to build the cage. The widely spreading $\mathrm{HOMO}$ of $\mathrm{Li}_{4} \mathrm{~S}$ suggests more clearly the lithium cage formation in the molecule. The SOMO of $\mathrm{Li}_{3} \mathrm{~S}$ and $\mathrm{HOMO}$ of $\mathrm{Li}_{4} \mathrm{~S}$ are antibonding between the $\mathrm{Li}$ and $\mathrm{S}$ atoms, but are bonding between all pairs of lithium atoms in these molecules. In spite of the antibonding character of SOMO and HOMO, the central S atom is bound to lithiums through an electrostatic interaction.

Charge populations calculated by the natural bond orbital (NBO) analysis ${ }^{51}$ on the central atoms in $\mathrm{Li}_{n} \mathrm{~A}$ were -0.93 for $\mathrm{C}$ in $\mathrm{Li}_{6} \mathrm{C},-0.87$ for $\mathrm{O}$ in $\mathrm{Li}_{3} \mathrm{O},-1.89$ for $\mathrm{S}$ in $\mathrm{Li}_{3} \mathrm{~S}$, and -1.92 for $\mathrm{S}$ in $\mathrm{Li}_{4} \mathrm{~S}$. The calculated charges on $\mathrm{C}, \mathrm{O}$, and $\mathrm{S}$ do not increase appreciably as more $\mathrm{Li}$ atoms are added; e.g., $\mathrm{Li}_{4} \mathrm{C}(\mathrm{C}$, $-0.81), \mathrm{Li}_{2} \mathrm{O}(\mathrm{O},-0.81)$, and $\mathrm{Li}_{2} \mathrm{~S}(\mathrm{~S},-1.84)$. The fact indicates that the excess valence electron is not associated with the central atom and that the central atom remains content with its normal octet. ${ }^{5,15}$ For hyperlithiated $\mathrm{Li}_{n} \mathrm{~A}$ molecules, therefore, it is concluded that the electronegative central atom $\left(\mathrm{A}^{m-}\right)$ is embedded in the $\mathrm{Li}_{n}{ }^{m+}$ cage. Although the $\mathrm{Li}-\mathrm{A}$ bond is antibonding in character, the electrostatic attraction between $\mathrm{Li}_{n}{ }^{m+}$ and $\mathrm{A}^{m-}$ would play a role in enhancing the overall stability of neutral $\mathrm{Li}_{n} \mathrm{~A}$ molecules.

As listed in Table $1, \mathrm{M}_{2} \mathrm{CN}(\mathrm{M}=\mathrm{Li}, \mathrm{Na}, \mathrm{K})$ molecules with one excess valence electron are all stable toward the dissociation to give $\mathrm{M}$ and $\mathrm{MCN} .{ }^{28-32}$ Of these hypervalent molecules,

TABLE 1: Dissociation Energies $\left(D_{0}{ }^{\circ}\right)$ and Ionization Energies (IE) of Hyperlithiated and Hypervalent Molecules

\begin{tabular}{|c|c|c|c|c|c|}
\hline \multirow{2}{*}{$\begin{array}{l}\text { Number of } \\
\text { excess } \\
\text { valence electrons }\end{array}$} & \multirow[t]{2}{*}{$\begin{array}{c}\text { Molecule } \\
\text { (Point group) }\end{array}$} & \multicolumn{2}{|c|}{$\begin{array}{c}D_{0}^{\circ} / \mathrm{kJ} \text { mol } \\
\mathrm{M}_{n} \mathrm{~A}(\mathrm{~g}) \rightarrow \mathrm{M}_{n-1} \mathrm{~A}(\mathrm{~g})+\mathrm{M}(\mathrm{g})\end{array}$} & \multicolumn{2}{|c|}{$\begin{array}{c}\mathrm{IE} / \mathrm{eV} \\
\mathrm{M}_{n} \mathrm{~A} \rightarrow \mathrm{M}_{n} \mathrm{~A}^{+}\end{array}$} \\
\hline & & Theor. & Expt. & Theor. ${ }^{a}$ & Expt. \\
\hline \multirow[t]{3}{*}{1} & $\mathrm{Li}_{3} \mathrm{O}\left(D_{3 \mathrm{~h}}\right)$ & $198.3^{\mathrm{b}}$ & $212 \pm 42$ & $3.48^{\mathrm{b}}$ & $3.6 \pm 0.1$ \\
\hline & $\mathrm{Li}_{3} \mathrm{~S}\left(C_{3 \mathrm{v}}\right)$ & 148.5 & $138 \pm 14$ & 4.11 & $4.4 \pm 0.2$ \\
\hline & $\mathrm{Li}_{4} \mathrm{P}\left(T_{\mathrm{d}}\right)$ & 141.8 & $86 \pm 24$ & $3.40^{\mathrm{b}}$ & - \\
\hline \multirow[t]{3}{*}{2} & $\mathrm{CLi}_{6}\left(O_{\mathrm{h}}\right)$ & $(273)^{\mathrm{c}}$ & $(274 \pm 11)^{\mathrm{c}}$ & $4.08^{\mathrm{b}}$ & - \\
\hline & $\mathrm{Li}_{4} \mathrm{O}\left(T_{\mathrm{d}}\right)$ & $120.9^{b}$ & $197 \pm 30$ & $4.71^{\mathrm{b}}$ & - \\
\hline & $\mathrm{Li}_{4} \mathrm{~S}\left(C_{2 \mathrm{v}}\right)$ & $123.2^{\mathrm{b}}$ & $212 \pm 13$ & 4.09 & - \\
\hline \multirow[t]{3}{*}{1} & $\mathrm{Li}_{2} \mathrm{CN}\left(C_{\mathrm{s}}\right)$ & 103.8 & $137 \pm 14$ & 5.13 & $5.4 \pm 0.2$ \\
\hline & $\mathrm{Na}_{2} \mathrm{CN}\left(C_{\mathrm{s}}\right)$ & 72.8 & $104 \pm 14$ & 4.66 & $4.9 \pm 0.2$ \\
\hline & $\mathrm{K}_{2} \mathrm{CN} \quad\left(C_{\mathrm{s}}\right)$ & 74.5 & $82 \pm 8$ & 3.70 & $4.5 \pm 0.5$ \\
\hline
\end{tabular}

\footnotetext{
${ }^{a}$ Vertical ionization energy (vIE).

${ }^{\mathrm{b}}$ Schleyer et al. ${ }^{5,6,15}$

$\mathrm{CLi}_{6}(\mathrm{~g}) \rightarrow \mathrm{CLi}_{4}(\mathrm{~g})+\mathrm{Li}_{2}(\mathrm{~g})$ process
} 
$\mathrm{Li}_{2} \mathrm{CN} 1\left(D_{0}{ }^{\circ}=137 \mathrm{~kJ} / \mathrm{mol}\right)$ is the most stable. Each of $\mathrm{M}_{2} \mathrm{CN}$ molecules has several structural isomers with a global minimum. Figure 2 illustrates molecular structures of all isomers of $\mathrm{Li}_{2} \mathrm{CN}$ calculated at the MP2(FC)/6-31-G* level, together with the SOMOs of the planar $\mathbf{1}$ and linear $\mathbf{4}$ isomers. The optimized geometries calculated for $\mathrm{Na}_{2} \mathrm{CN}$ and $\mathrm{K}_{2} \mathrm{CN}$ at the MP2(FU)/6-31-G* level also gave four structural isomers to each molecule, similar to the case of $\mathrm{Li}_{2} \mathrm{CN}$. For $\mathrm{M}_{2} \mathrm{CN}$, the most stable isomer in the planar structure with $C_{\mathrm{s}}$ symmetry is a hypervalent molecule in which the excess valence electron delocalizes over the two alkali-metal atoms forming a $\mathrm{M}_{2}{ }^{+}$ cation. The IEs observed for these molecules, $5.4 \pm 0.4 \mathrm{eV}$ for $\mathrm{Li}_{2} \mathrm{CN}, 4.9 \pm 0.2 \mathrm{eV}$ for $\mathrm{Na}_{2} \mathrm{CN}, 4.5 \pm 0.5 \mathrm{eV}$ for $\mathrm{K}_{2} \mathrm{CN}$, are close to those for $\mathrm{Li}_{2} \rightarrow \mathrm{Li}_{2}^{+}(4.9 \mathrm{eV}), \mathrm{Na}_{2} \rightarrow \mathrm{Na}_{2}^{+}(4.9 \mathrm{eV})$, and $\mathrm{K}_{2} \rightarrow \mathrm{K}_{2}^{+}(4.1 \mathrm{eV})$. The fact suggests that the ionization occurs from the SOMO. $\mathrm{M}_{2} \mathrm{CN}$ molecules possessing the $\mathrm{M}_{2}^{+}$ unit in it can be described as $\mathrm{M}_{2}{ }^{+} \mathrm{CN}^{-}$. On the other hand, the linear isomers of $\mathrm{M}_{2} \mathrm{CN}$, that are less stable than the planar isomers, would be complexes described as $\mathrm{M}^{+} \mathrm{CN}^{-} \cdot \mathrm{M}$ and $\mathrm{M} \cdot \mathrm{CN}^{-} \mathrm{M}^{+}$; these are "electronomers" or electronic isomers in which the localization of the excess valence electron is different each other.

\section{3. $\operatorname{Li}_{2} \mathbf{F}$ Molecule and $\operatorname{Li}_{2} \mathbf{F}_{n-1}(n=3,4)$ Clusters}

Although theoretically predicted hyperlithiated $\mathrm{Li}_{2} \mathrm{~F}$ was hardly observed with Knudsen-effusion mass spectrometry, it was eventually detected in a supersonic beam of vapors generated by laser ablation of a solid mixture of $\mathrm{LiF}$ and $\mathrm{Li}_{3} \mathrm{~N}$. ${ }^{33-34}$
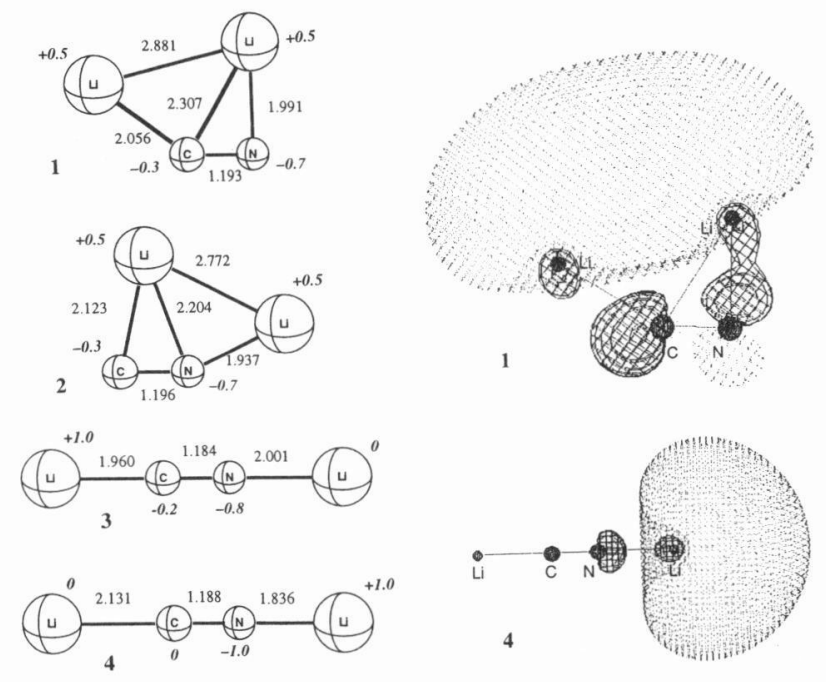

Figure 2. Structural isomers of $\mathrm{Li}_{2} \mathrm{CN}$ and features of SOMO of the planar isomers $1\left[\mathrm{Li}_{2}^{+}(\mathrm{CN})^{-}\right]$and the linear isomer $4\left[\mathrm{Li} \cdot(\mathrm{CN})^{-} \mathrm{Li}^{+}\right]$ deduced from calculations at MP2(FC)/6-31-G*; roman letters are the bond length in $\AA$ and italic letters the natural charge.
In addition, new clusters $\mathrm{Li}_{n} \mathrm{~F}_{n-1}(n=3,4)$ with an excess electron were detected in the same supersonic beam. Table 2 lists the IEs of $\mathrm{Li}_{2} \mathrm{~F}_{n-1}(n=2-4)$ species determined by photoionization, together with the dissociation energy $\left(D_{0}{ }^{\circ}\right)$ of the isomers calculated at the MP2(FULL)/6-311+G(d)//B3LYP/6$311+\mathrm{G}(\mathrm{d})$ level of theory. Figure 3 illustrates the theoretically deduced structures of $\mathrm{Li}_{n} \mathrm{~F}_{n-1}(n=2-4)$ isomers.

The observed IE of $\mathrm{Li}_{2} \mathrm{~F}(3.78 \pm 0.3 \mathrm{eV})$ agrees well with the theoretical adiabatic IE $(\mathrm{aIE}=3.9 \mathrm{eV})$. This fact verifies a result of theoretical calculations that the $\mathrm{Li}_{2} \mathrm{~F}$ molecule (1a) is one of the hyperlithiated molecules and the excess valence electron delocalizes on the two $\mathrm{Li}$ atoms. Also, the fact that IE of $\mathrm{Li}_{2} \mathrm{~F}$ is significantly lower than that of the $\mathrm{Li}$ atom $(5.39 \mathrm{eV})$ is ascribed to the antibonding character of the SOMO between the $\mathrm{Li}$ and $\mathrm{F}$ atoms, as described by Gutsev and Boldyrev for "superalkali" species. ${ }^{52}$ Although the presence of the isomer $\mathbf{1 b}$ is suggested theoretically, only the isomer 1a existed in the supersonic beam because 1a $\left(D_{0}{ }^{0}=147.4 \mathrm{~kJ} / \mathrm{mol}\right)$ is more

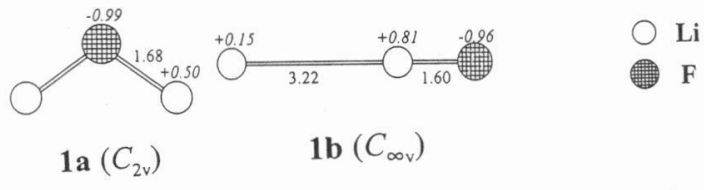

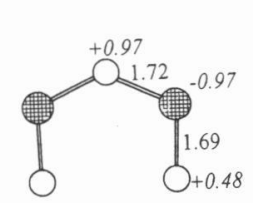

$\mathbf{2 a}\left(C_{2 v}\right)$

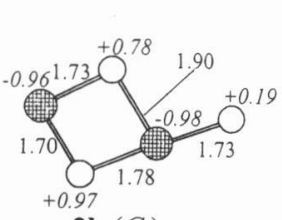

$2 \mathbf{b}\left(C_{\mathrm{s}}\right)$

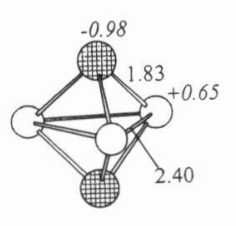

$2 \mathrm{c}\left(D_{3 \mathrm{~h}}\right)$

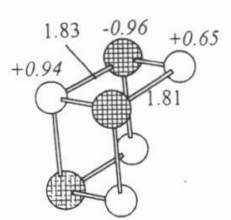

$3 \mathbf{a}\left(C_{3 v}\right)$

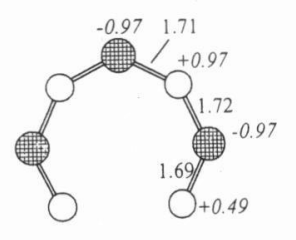

$3 \mathrm{c}\left(C_{2 \mathrm{v}}\right)$

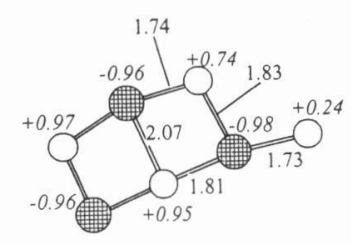

$3 \mathbf{b}\left(C_{s}\right)$

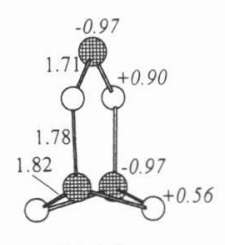

$3 \mathrm{~d}\left(C_{2 v}\right)$
Figure 3. Structural isomers of $\mathrm{Li}_{2} \mathrm{~F}_{n-1}(n=2-4)$ obtained by calculations at B3LYP/6-311+G(d); roman letters are the bond length in $\AA$ and italic letters the natural charge.

TABLE 2: Ionization Energies and Dissociation Energies of $\operatorname{Li}_{n} \mathbf{F}_{n-1}(n=2-4)$

\begin{tabular}{|c|c|c|c|c|c|c|}
\hline & $\begin{array}{c}\text { Experimental } \\
\text { IE/eV }\end{array}$ & Isomer & $\mathrm{vIE} / \mathrm{eV}^{\mathrm{a}}$ & $\begin{array}{c}\text { Theoretical } \\
\text { aIE/eV }{ }^{\mathrm{a}}\end{array}$ & $D_{0}{ }^{\circ} / \mathrm{kJ} \mathrm{mol}^{-1 \mathrm{~b}}$ & Classification $^{\mathrm{c}}$ \\
\hline \multirow[t]{2}{*}{$\mathrm{Li}_{2} \mathrm{~F}$} & $3.78 \pm 0.20$ & $1 \mathbf{a}\left(C_{2 \mathbf{v}}\right)$ & 4.43 & 3.86 & 147.4 & HLC \\
\hline & & $\mathbf{1 b}\left(C_{\infty \mathrm{V}}\right)$ & 6.84 & - & 26.7 & $\mathrm{SC}$ \\
\hline \multirow{3}{*}{$\mathrm{Li}_{3} \mathrm{~F}_{2}$} & $4.32 \pm 0.20$ & $\mathbf{2 a}\left(C_{2 \mathrm{v}}\right)$ & 5.26 & 3.78 & 97.8 & $\mathrm{SC}$ (planar) \\
\hline & & $2 \mathbf{b}\left(C_{\mathrm{s}}\right)$ & 4.51 & 4.15 & 94.9 & SC (Li-tail) \\
\hline & & $2 \mathrm{c}\left(D_{3 \mathrm{~h}}\right)$ & 3.78 & 3.78 & 33.0 & HLC \\
\hline \multirow[t]{4}{*}{$\mathrm{Li}_{4} \mathrm{~F}_{3}$} & $4.30 \pm 0.20$ & $\mathbf{3 a}\left(C_{3 \mathrm{v}}\right)$ & 4.26 & 3.61 & 87.4 & $\mathrm{SC}$ \\
\hline & & $\mathbf{3 b}\left(C_{\mathrm{s}}\right)$ & 4.53 & 4.06 & 74.8 & SC (Li-tail) \\
\hline & & $3 \mathrm{c}\left(C_{2 \mathrm{v}}\right)$ & 5.58 & 3.87 & 66.2 & $\mathrm{SC}$ (planar) \\
\hline & & $3 \mathbf{d}\left(C_{2 \mathrm{v}}\right)$ & 3.46 & - & 52.8 & $\mathrm{SC}$ \\
\hline
\end{tabular}

\footnotetext{
${ }^{a}$ Vertical and adiabatic ionization energies (vIE and aIE) at MP2(FULL)/6-311+G(d)// B3LYP/6-311+G(d).

${ }^{\text {b }}$ At B3LYP/6-311+G(d).

${ }^{\mathrm{c}} \mathrm{HLC}$, the hyperlithiated configuration; SC, the segregated configuration.
} 
stable than $\mathbf{1 b}\left(D_{0}{ }^{\circ}=26.7 \mathrm{~kJ} / \mathrm{mol}\right)$. The isomer $\mathbf{1 b}$ is in a segregated configuration (SC).

The observed IE of $\mathrm{Li}_{3} \mathrm{~F}_{2}(4.32 \mathrm{eV})$ indicates the predominance of SC in this cluster. This IE value is close to aIE calculated for the isomer $\mathbf{2} \mathbf{b}$, which is in SC with $D_{0}{ }^{\circ}=94.9 \mathrm{~kJ} / \mathrm{mol}$. Here, one can consider that the isomer $\mathbf{2} \mathbf{a}$ in another SC with a similar stability $\left(D_{0}{ }^{\circ}=94.9 \mathrm{~kJ} / \mathrm{mol}\right)$ would be present because the observed IE is in between the theoretical aIE and vertical ionization energy (vIE) of $\mathbf{2} \mathbf{a}$. However, the presence of $\mathbf{2} \mathbf{a}$ in the supersonic beam is denied from a comparison of IECs between the experiment and the simulation shown in Figure 4; the theoretical IEC was obtained by taking account of the Franck-Condon factor for the ionization process, the detail of which will be described elsewhere. The isomer $\mathbf{2 c}$ with a hyperlithiated configuration (HLC) is obviously minor, because the observed IE $(4.32 \mathrm{eV})$ is significantly higher in energy than vIE calculated for $2 \mathrm{c}(3.7 \mathrm{eV})$. Furthermore, the dissociation energy of $\mathbf{2 c}$ is calculated to be quite small $\left(D_{0}{ }^{\circ}=\right.$ $33.0 \mathrm{~kJ} / \mathrm{mol}$ ) in comparison with the other isomers of $\mathrm{Li}_{3} \mathrm{~F}_{2}$ as listed in Table 2. The $\mathrm{Li}_{4} \mathrm{~F}_{3}$ cluster would prefer $\mathrm{SC}$. The IE observed for $\mathrm{Li}_{4} \mathrm{~F}_{3}(4.3 \mathrm{eV})$ is close to vIEs calculated for $\mathbf{3 a}$ and $\mathbf{3 b}$, both of which are in SC. No big difference is seen in dissociation energies between $87.4 \mathrm{~kJ} / \mathrm{mol}$ for $\mathbf{3 a}$ and 74.8 $\mathrm{kJ} / \mathrm{mol}$ for $\mathbf{3 b}$, but the shape of IEC shown in Figure 4 indicates that the isomer detected in the supersonic beam is $\mathbf{3 b}$.

In the $\mathrm{Li}_{n} \mathrm{~F}_{n-1}$ system, $\mathrm{Li}_{2} \mathrm{~F}$ is a hypervalent molecule, but $\mathrm{Li}_{3} \mathrm{~F}_{2}$ prefers to be in SC despite a possibility to be in HLC. Every isomer of $\mathrm{Li}_{4} \mathrm{~F}_{3}$ is in SC. Thus, at $n \geq 3$ the $\mathrm{Li}_{n} \mathrm{~F}_{n-1}$ clusters tends to take SC in which the excess valence electron is localized at any of the $\mathrm{Li}$ atom.

\section{4. $\mathrm{Li}_{2} \mathrm{OH}$ Molecule and $\mathrm{Li}_{n}(\mathrm{OH})_{n-1}(n=3-5)$ Clusters}

To detect $\mathrm{Li}_{n}(\mathrm{OH})_{n-1}(n=2-5)$ species, we injected small amounts of water vapor diluted with air into an laser ablation

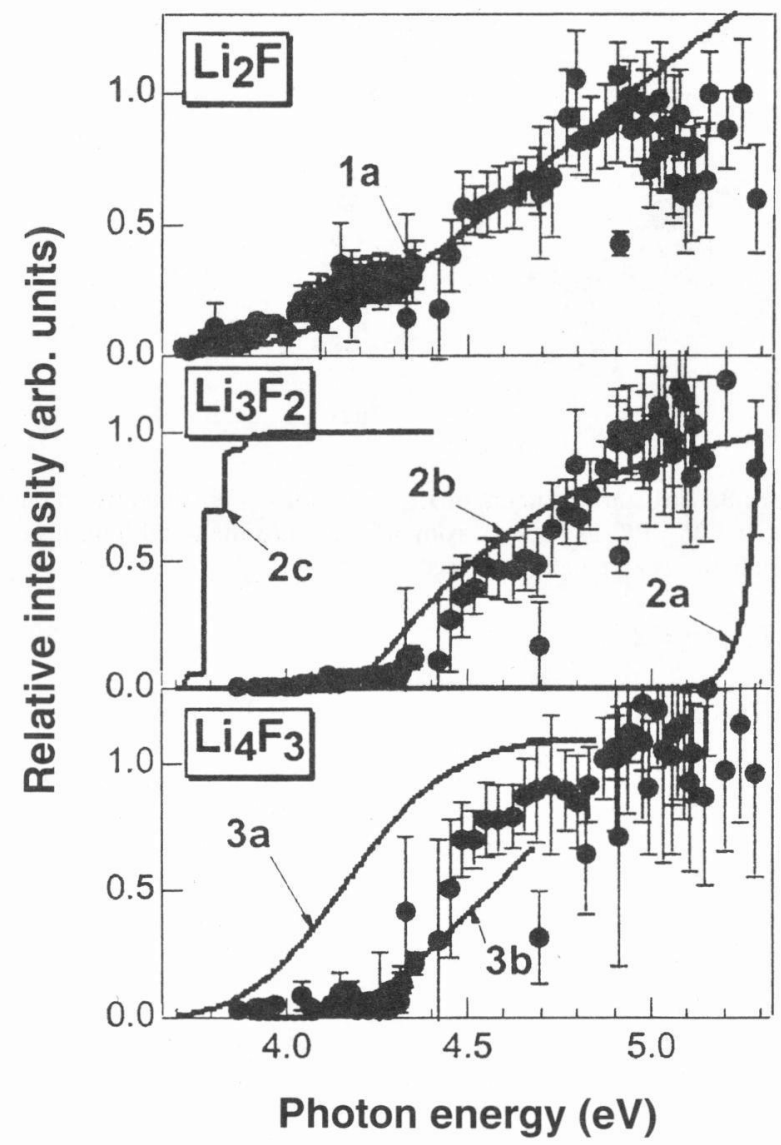

Figure 4. Ionization efficiency curves (IECs) observed for $\mathrm{Li}_{2} \mathrm{~F}_{n-1}$ ( $n=2-4)$ in comparison with simulations based on Franck-Condon factors. source in which lithium metal pressed on a sample disk was irradiated by $532 \mathrm{~nm}$ laser pulses. Figure 5 shows ionization efficiency curves (IECs) of the $\mathrm{Li}_{2}(\mathrm{OH})$ molecule as well as $\mathrm{Li}_{n}(\mathrm{OH})_{n-1}(n=3-5)$ clusters. $^{36}$ The experimental values of IE determined here for each isomer of these species are summarized in Table 3, together with both the theoretical vertical ionization energy (vIE) and adiabatic ionization energy (aIE) calculated at the MP2(FULL)/6-311+G(d)//B3LYP/6$311+\mathrm{G}(\mathrm{d})$ level as well as the dissociation energies calculated at the B3LYP/6-311+G(d,p) level. The structural isomers and features of SOMO of $\mathrm{Li}_{2}(\mathrm{OH})$ and $\mathrm{Li}_{3}(\mathrm{OH})_{2}$ deduced by theoretical calculations at the $\mathrm{B} 3 \mathrm{LYP} / 6-311+\mathrm{G}(\mathrm{d}, \mathrm{p})$ level are illustrated in Figure 6. The theoretically obtained molecular structures and isosurfaces of SOMO of $\mathrm{Li}_{4}(\mathrm{OH})_{3}$ and $\mathrm{Li}_{5}(\mathrm{OH})_{4}$ are shown in Figures 7 and 8, respectively.

The results of our theoretical investigation reveal that IEs of $\mathrm{Li}_{n}(\mathrm{OH})_{n-1}(n=2-5)$ species with an excess lithium atom depend largely on their structure. ${ }^{35}$ Every cluster has several stable structural isomers, the structure of which is closely related to the charge population associated with the location of the excess valence electron of the $\mathrm{Li}$ atom. In some isomers, the excess electron delocalizes over all of the lithium atoms in the cluster, forming a metallic network $\left(\mathrm{Li}_{n}{ }^{+}\right)$similar to hyperlithiated molecules like $\mathrm{Li}_{3} \mathrm{O}$ and $\mathrm{Li}_{6} \mathrm{C}$. In other isomers, the excess valence electron localizes at a specific site, making the metallic and ionic parts segregated. In the $\mathrm{Li}_{n}(\mathrm{OH})_{n-1}(n=2-$ 5) system, the isomers 1a and 2a seem to have HLC with respect to the charge population. All of the lithium atoms possess almost the same atomic charge in these isomers as

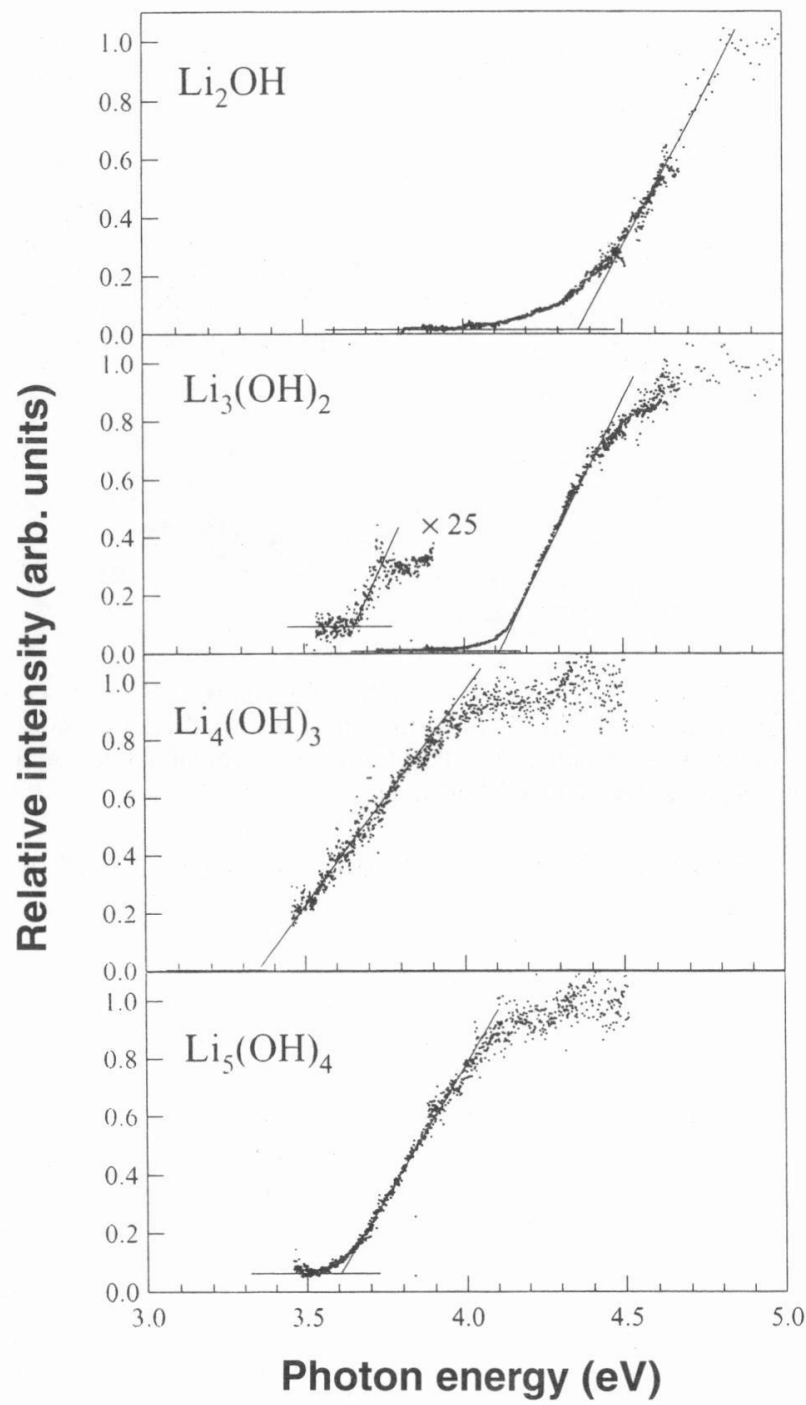

Figure 5. Ionization efficiency curves (IECs) of $\mathrm{Li}_{2}(\mathrm{OH})$ and $\mathrm{Li}_{n}(\mathrm{OH})_{n-1}(n=3-5)$ clusters measured by photoionization 
shown in Figures 6 and 7. To confirm whether or not these isomers are in HLC, we examined their electronic structure and stability in terms of a character of SOMO which accommodates the excess electron. As described in the previous section, hyperlithiated molecules $\mathrm{Li}_{3} \mathrm{O}, \mathrm{Li}_{6} \mathrm{C}$, and $\mathrm{Li}_{3} \mathrm{~S}$ are stabilized by an electrostatic attraction between the anionic center and the cationic lithium network which is maintained by sharing the excess electron. The SOMO spatially covers all lithium atoms, making their structures highly symmetric; e.g., $D_{3 \mathrm{~h}}$ for $\mathrm{Li}_{3} \mathrm{O}, O_{\mathrm{h}}$ for $\mathrm{Li}_{6} \mathrm{C}$, and $C_{3 \mathrm{v}}$ for $\mathrm{Li}_{3} \mathrm{~S}$. The $\mathrm{SOMO}$ should have an antibonding character between, at least, one of the lithium atoms and the central atom. However, the equal posi-
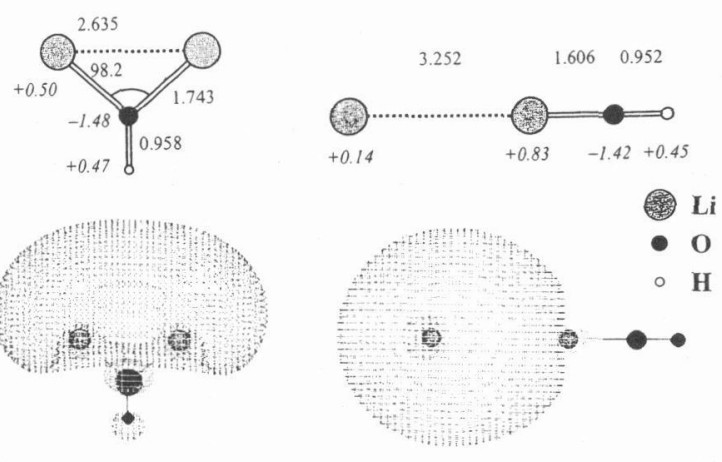

$1 \mathbf{a}\left(C_{2 \mathrm{v}}\right)$

$1 \mathbf{b}\left(C_{\infty v}\right)$
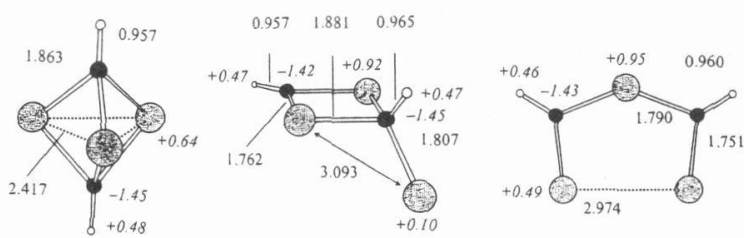

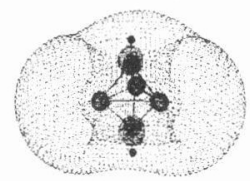

2a $\left(D_{3 \mathrm{~h}}\right)$

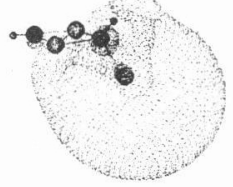

$2 \mathbf{b}\left(C_{s}\right)$

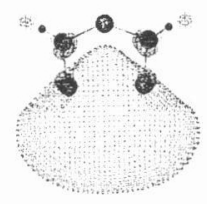

$2 \mathfrak{c}\left(C_{2 v}\right)$
Figure 6. Structures and features of $\mathrm{SOMO}$ of $\mathrm{Li}_{2}(\mathrm{OH})$ and $\mathrm{Li}_{3}(\mathrm{OH})_{2}$ obtained by calculations at B3LPY/6-311+G(d,p); roman letters are the bond length in $\AA$ and italic letters the natural charge. tive charge on all lithiums produces an equal electrostatic attraction between each $\mathrm{Li}$ atom and the central atom. The SOMO spreading over the whole lithium network plays a key role in the formation of molecules with HLC.

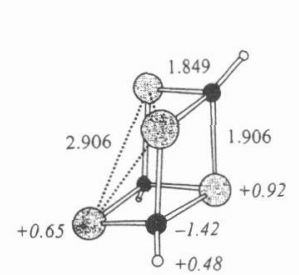

3a $\left(C_{3 v}\right)$

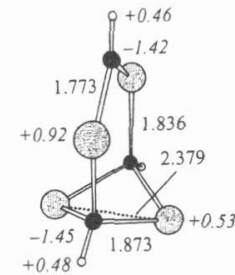

$3 \mathbf{b}\left(C_{2 v}\right)$

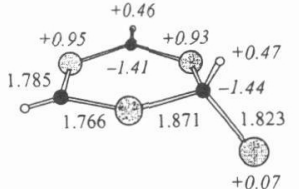

$3 \mathbf{c}\left(C_{\mathrm{s}}\right)$
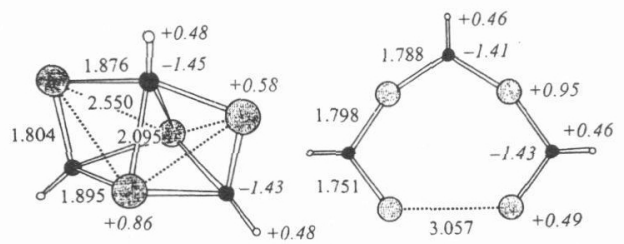

3d $\left(C_{2 v}\right)$ $3 \mathbf{e}\left(C_{2 v}\right)$

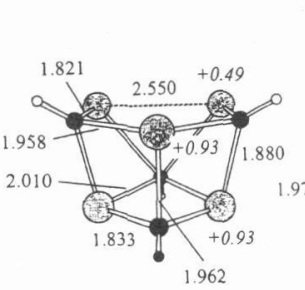

$4 \mathrm{a}\left(C_{\mathrm{s}}\right)$

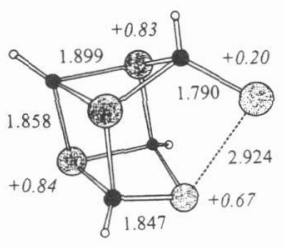

$4 d\left(C_{s}\right)$

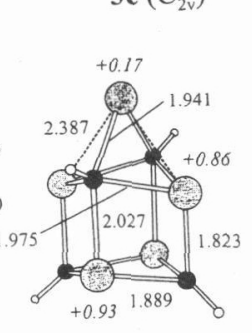

$4 \mathbf{b}\left(C_{2 v}\right)$

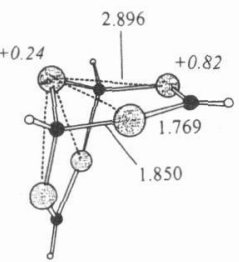

$4 \mathrm{e}\left(C_{2 v}\right)$

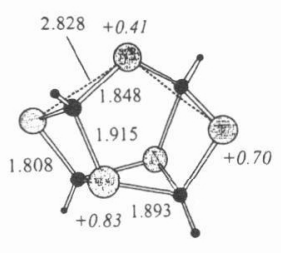

$4 c\left(C_{2}\right)$
Figure 7. Structural isomers of $\mathrm{Li}_{4}(\mathrm{OH})_{3}$ and $\mathrm{Li}_{5}(\mathrm{OH})_{4}$ obtained by calculations at B3LPY $/ 6-311+\mathrm{G}(\mathrm{d}, \mathrm{p})$; roman letters are the bond length in $\AA$ and italic letters the natural charge.

TABLE 3: Ionization Energies and Dissociation Energies of $\mathrm{Li}_{n}(\mathrm{OH})_{n-1}(n=2-5)$

\begin{tabular}{|c|c|c|c|c|c|c|}
\hline & $\begin{array}{c}\text { Experimental } \\
\mathrm{IE} / \mathrm{eV}\end{array}$ & Isomer & $\mathrm{vIE} / \mathrm{eV}^{\mathrm{a}}$ & $\begin{array}{c}\text { Theoretical } \\
\mathrm{aIE} / \mathrm{eV}^{\text {a }}\end{array}$ & $D_{0}{ }^{\circ} / \mathrm{kJ} \mathrm{mol}^{-1 \mathrm{~b}}$ & Classification $^{\circ}$ \\
\hline \multirow[t]{2}{*}{$\mathrm{Li}_{2} \mathrm{OH}$} & $4.35 \pm 0.12$ & $1 \mathbf{a}\left(C_{2 \mathrm{v}}\right)$ & 4.45 & 4.03 & 146.7 & HLC \\
\hline & & $\mathbf{1 b}\left(C_{\infty \mathrm{V}}\right)$ & 6.58 & 5.55 & 19.4 & $\mathrm{SC}$ \\
\hline \multirow[t]{3}{*}{$\mathrm{Li}_{3}(\mathrm{OH})_{2}$} & $3.66 \pm 0.02$ & $\mathbf{2 a}\left(D_{3 \mathrm{~h}}\right)$ & 3.57 & 3.57 & 92.5 & HLC \\
\hline & $4.16 \pm 0.04$ & $2 \mathbf{b}\left(C_{\mathrm{s}}\right)$ & 4.13 & 4.13 & 92.0 & SC (Li-tail) \\
\hline & & $2 \mathrm{c}\left(C_{2 \mathrm{v}}\right)$ & 5.10 & 4.17 & 82.6 & SC (planar) \\
\hline \multirow[t]{5}{*}{$\mathrm{Li}_{4}(\mathrm{OH})_{3}$} & $3.33 \pm 0.11$ & $\mathbf{3 a}\left(C_{3 v}\right)$ & 3.40 & 3.38 & 120.1 & $\mathrm{SC}$ \\
\hline & & $\mathbf{3 b}\left(C_{2 \mathrm{v}}\right)$ & 3.31 & 3.31 & 88.7 & $\mathrm{SC}$ \\
\hline & & $3 \mathbf{c}\left(C_{\mathrm{s}}\right)$ & 4.21 & 2.96 & 81.7 & $\mathrm{SC}$ (Li-tail) \\
\hline & & $\mathbf{3 d}\left(C_{2 \mathrm{v}}\right)$ & 3.29 & 3.29 & 81.6 & $(\mathrm{SC})$ \\
\hline & & $\mathbf{3 e}\left(C_{2 \mathrm{v}}\right)$ & 5.46 & 4.28 & 46.5 & SC (planar) \\
\hline \multirow[t]{6}{*}{$\mathrm{Li}_{5}(\mathrm{OH})_{4}$} & $3.60 \pm 0.11$ & $4 \mathbf{a}\left(C_{\mathrm{s}}\right)$ & 3.71 & 3.18 & 80.9 & $\mathrm{SC}$ \\
\hline & & $4 \mathbf{b}\left(C_{2 v}\right)$ & 3.55 & 3.23 & 79.6 & $\mathrm{SC}$ \\
\hline & & $\mathbf{4 c}\left(C_{2}\right)$ & 3.05 & 3.01 & 76.4 & $(\mathrm{SC})$ \\
\hline & & $\mathbf{4 d}\left(C_{\mathrm{s}}\right)$ & 4.18 & 3.82 & 71.9 & $\mathrm{SC}$ (Li-tail) \\
\hline & & $4 \mathbf{e}\left(C_{2 \mathrm{v}}\right)$ & 3.19 & 2.86 & 47.1 & $\mathrm{SC}$ \\
\hline & & $4 \mathbf{f}\left(C_{2 \mathrm{v}}\right)$ & 5.62 & 4.41 & 12.5 & SC (planar) \\
\hline
\end{tabular}

\footnotetext{
${ }^{a}$ Vertical and adiabatic ionization energies (vIE and aIE) at MP2/6-311+G(d,p).
}

${ }^{\mathrm{b}}$ At B3LYP/6-311+G(d,p).

${ }^{\mathrm{c}} \mathrm{HLC}$, the hyperlithiated configuration; SC, the segregated configuration. 
The result of theoretical calculations indicates further that IEs of the isomers of $\mathrm{Li}_{n}(\mathrm{OH})_{n-1}$ depend on the number of terminal lithium atoms as shown in Figure 9, irrespective of the stability toward dissociation (Table 3 ). For example, the difference in IEs between the isomer $\mathbf{2 a}$ and $\mathbf{2} \mathbf{c}$ of $\mathrm{Li}_{3}(\mathrm{OH})_{2}$ is as large as $1.43 \mathrm{eV}$, although the difference in the dissociation energies is only $0.1 \mathrm{eV}(9.9 \mathrm{~kJ} / \mathrm{mol})$. The IEs of planar isomers $(\mathbf{1 a}, \mathbf{2 c}, \mathbf{3 e}, \mathbf{4 f})$ with two terminal lithiums $\left(n_{\mathrm{TL}}=2\right)$ tend to increase from 4.5 to $5.6 \mathrm{eV}$ with an increase of $n$. The IE of Li-tail isomers $(\mathbf{2 b}, \mathbf{3 c}, \mathbf{4 d})$ with $n_{\mathrm{TL}}=1$ is around $4.2 \mathrm{eV}$ independent of $n$. The isomers without terminal $\mathrm{Li}$ atoms have IE lower than $3.7 \mathrm{eV}$. The vIE of the linear isomer $\mathbf{1 b}(6.58$ $\mathrm{eV})$ is quite higher than that of the $\mathrm{Li}$ atom $(5.39 \mathrm{eV})$.

Based on the Koopmans theorem that the vertical ionization energy directly corresponds to the orbital energy of SOMO, the present result is explained by considering the stability of SOMO, from which the extra electron is removed in the ionization process. In the $\mathrm{Li}_{n}(\mathrm{OH})_{n-1}$ clusters, the $\mathrm{OH}^{-}$groups with negative charge would deform the SOMO as a consequence of the electronic repulsion as suggested from the spatial distribution of SOMO. When repulsion by $\mathrm{OH}^{-}$groups becomes larger, the SOMO becomes less stable and then the ionization energy becomes lower. This leads to the importance of spatial arrangement of the $\mathrm{OH}^{-}$groups against the SOMO within the cluster. We focus the discussion on the spatial distribution of the SOMO to explain the correlation between the ionization energy and the number of terminal lithium atoms in the $\mathrm{Li}_{n}(\mathrm{OH})_{n-1}$ clusters. The SOMO tends to localize around the terminal lithium atom. In the planar isomers with the highest IE, the SOMO distributes in a space between the two terminal lithium atoms, independent of the cluster size. The deformation of SOMO from a spherical symmetry is rather small in these planar isomers, because the neighboring $\mathrm{OH}^{-}$is fairly distant from the SOMO. In the Li-tail isomers with the second highest ionization energy in each size of the cluster, the SOMO localizes around the terminal $\mathrm{Li}$ atom and is deformed by the nearest $\mathrm{OH}^{-}$group as seen in $\mathbf{2 b}$ (Figure 6). It is to be

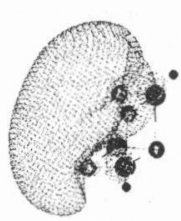

$3 \mathbf{a}$

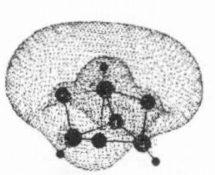

3d

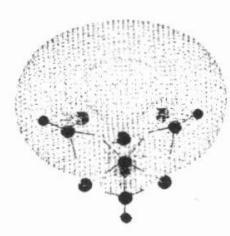

4a

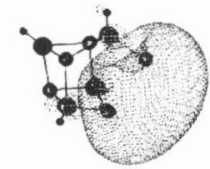

4d

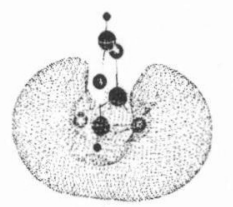

3b

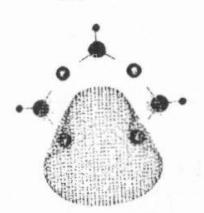

$3 \mathrm{e}$

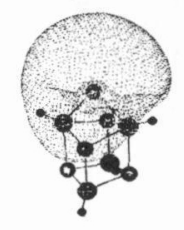

$4 \mathbf{b}$

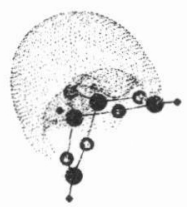

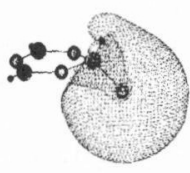

$3 c$
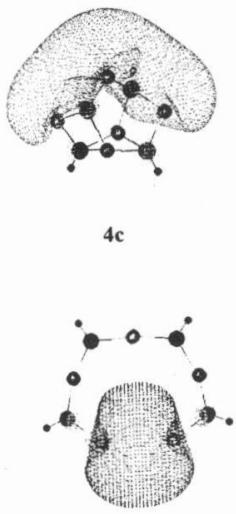

$4 \mathbf{f}$
Figure 8. Isosurfaces of SOMO in structural isomers of $\mathrm{Li}_{4}(\mathrm{OH})_{3}$ and $\mathrm{Li}_{5}(\mathrm{OH})_{4}$ obtained by calculations at B3LPY/6-311+G(d,p). noted that the Li-tail isomers in which the SOMO localizes around only one Li atom have lower ionization energy than the planar isomers in which the SOMO delocalizes between two Li atoms. In the isomers without terminal lithium, the SOMO delocalizes over the lithium network. In particular, the SOMO is largely deformed and widely distributed over the whole lithium network in the hyperlithiated isomers 2a (Figure 6). The ionization energies of these isomers are significantly low as seen in Table 3 .

From comparison of IEs between the experiment and the theory listed in Table 3 it is concluded that the isomers exited in the supersonic beam of the present experiment were $\mathrm{Li}_{2}(\mathrm{OH}) \mathbf{1 a}, \mathrm{Li}_{3}(\mathrm{OH})_{2} \mathbf{2} \mathbf{a}, \mathbf{2} \mathbf{b}, \mathrm{Li}_{4}(\mathrm{OH})_{3} \mathbf{3} \mathbf{a}$, and $\mathrm{Li}_{5}(\mathrm{OH})_{4} \mathbf{4 a}$. The global-minimum structure is in HLC at $n=2$ and 3 and in $\mathrm{SC}$ at $n=4$, indicating the occurrence of the transition from HLC to SC between $n=3$ and 4 . The second stable isomer $\mathbf{2 b}$ in $\mathrm{SC}$ was also observed for $\mathrm{Li}_{3}(\mathrm{OH})_{2}$. This might be attributed to nearly the same stability of the two isomers; $D_{0}{ }^{\circ}=92.5$ $\mathrm{kJ} / \mathrm{mol}$ for $\mathbf{1 a}$ and $D_{0}{ }^{\circ}=92.0 \mathrm{~kJ} / \mathrm{mol}$ for $\mathbf{2 b}$. The conclusion was also confirmed by comparing the shape of measured IECs with that obtained by simulations involving the FranckCondon factor (FCF), the detail of which is reported elsewhere. $^{35}$

\section{Reinvestigation of Molecular Structure and Ionization of $\mathrm{Li}_{3} \mathrm{O}$; Evidence for Electronomers}

When we reported the first evidence for the existence of hyperlithiated $\mathrm{Li}_{3} \mathrm{O},{ }^{1,2}$ the ionization energy (IE) determined by electron impact ionization was $4.5 \pm 0.2 \mathrm{eV}$. The dissociation energy of $\mathrm{Li}_{3} \mathrm{O}$ to give $\mathrm{Li}_{2} \mathrm{O}$ was determined as $212 \pm 42$ $\mathrm{kJ} / \mathrm{mol}$. Although the dissociation energy agreed considerably well with the theoretical value $(198.3 \mathrm{~kJ} / \mathrm{mol})$ calculated by Schleyer et al., ${ }^{5}$ a rather large difference was seen in the IE between the experiment and theory $(3.48 \mathrm{eV})$. The question remained to be solved for a long time. Recently, Lievens et al. have reported an experimental value $(3.54 \pm 0.3 \mathrm{eV})$ for IE of $\mathrm{Li}_{3} \mathrm{O}$ by photoionization measurements. ${ }^{40}$ This stimulated us to reinvestigate the ionization process of $\mathrm{Li}_{3} \mathrm{O}$ present in the same supersonic beam used for detecting the $\mathrm{Li}_{n}(\mathrm{OH})_{n-1}$

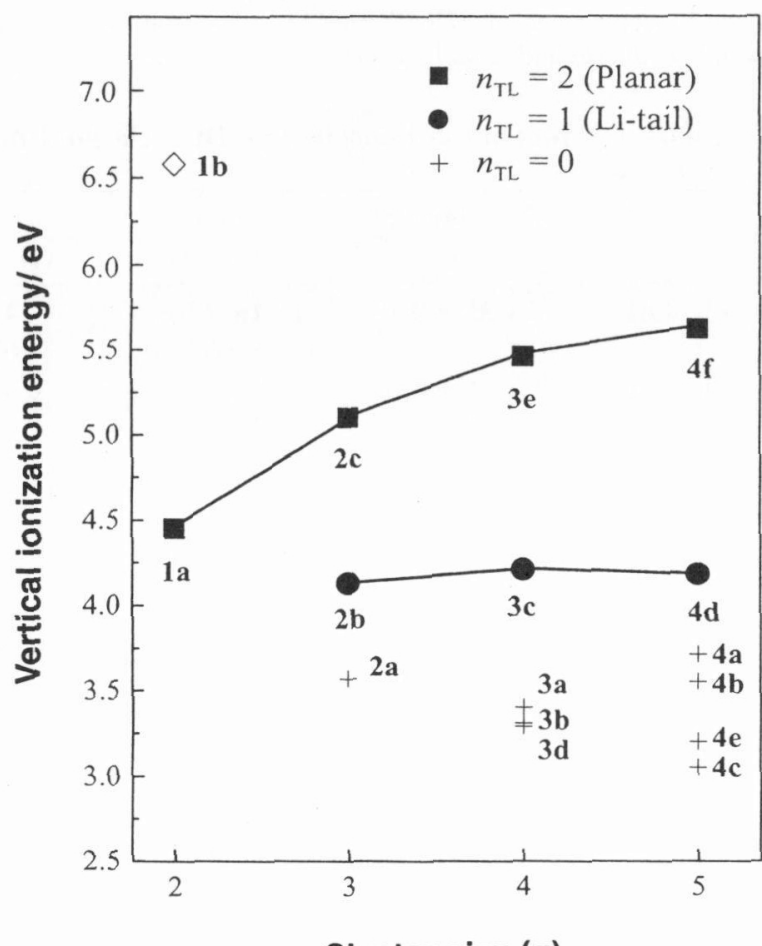

Cluster size ( $n)$

Figure 9. Relation between vertical ionization energy (vIE) and $n_{\mathrm{TL}}$ (the number of terminal lithium atoms) in each cluster size $n$. 
species described in the previous section. Figure 10(a) shows the ionization efficiency curve (IEC) for $\mathrm{Li}_{3} \mathrm{O}$ obtained by time-of-flight mass spectrometry combined with photoionization. There are two prominent features in the profile of IEC, i.e., two-stage rise and gradual linear rise between the threshold $(3.59 \pm 0.02 \mathrm{eV})$ and the second onset $(4.4 \pm 0.1 \mathrm{eV})$. The two-stage rise has already been reported by Lievens et al. ${ }^{40}$ and attributed to some ionization processes other than the first ionization of $\mathrm{Li}_{3} \mathrm{O}$ to give the ground state $\mathrm{Li}_{3} \mathrm{O}^{+}$of current interest. The threshold determined here is in excellent agreement with the theoretical IE. Both the theoretical vIE and aIE are calculated as $3.59 \mathrm{eV}$ at a sophisticated level of CCSD(T)/6-311+G(d) assuming the $D_{3 \mathrm{~h}}$ structure for the neutral geometry.

Schleyer et al. reported in 1982 that the most stable structure of $\mathrm{Li}_{3} \mathrm{O}$ was in $C_{2 \mathrm{v}}$ symmetry from the calculation at the HF/3$21 \mathrm{G}$ level, ${ }^{5}$ and then reported in 1992 that their higher level of calculation at MP2(FULL)/6-31+G* revealed the $D_{3 \mathrm{~h}}$ symmetry. ${ }^{6}$ Figure 11 illustrates the result of our calculation on molecular structures of neutral and ionic $\mathrm{Li}_{3} \mathrm{O}$ at the MP2/6$311+\mathrm{G}(\mathrm{d})$ level of $a b$ initio MO theory. ${ }^{53}$ For the neutral, both the $D_{3 \mathrm{~h}}$ and $C_{2 v}$ structures are local minima on the potential energy surface. Single-point energy calculations at the $\operatorname{CCSD}(\mathrm{T}) / 6-311+(\mathrm{d})$ level indicate that the $D_{3 \mathrm{~h}}$ structure is slightly favorable in energy $(0.8 \mathrm{~kJ} / \mathrm{mol})$, but the energy difference between those structures is much smaller than the accuracy of the calculation. The true minimal energy structure is still unpredictable. However, a simulation of the profile of IEC for $\mathrm{Li}_{3} \mathrm{O}$ shown in Figure 10(b) provided a new clue to the molecular structure.

We can make simulations of IEC for small molecules by a "direct counting of vibrational states" method, using the same procedure as applied to the $\mathrm{Li}_{n}(\mathrm{OH})_{n-1}$ system. ${ }^{36}$ An essential idea of simulation is to calculate Franck-Condon factors (FCF) within harmonic approximation. The calculation includes the displacement of molecular geometry, the frequency change, and the normal mode rotation between the neutral and cationic states. All of these parameters can be computed by density
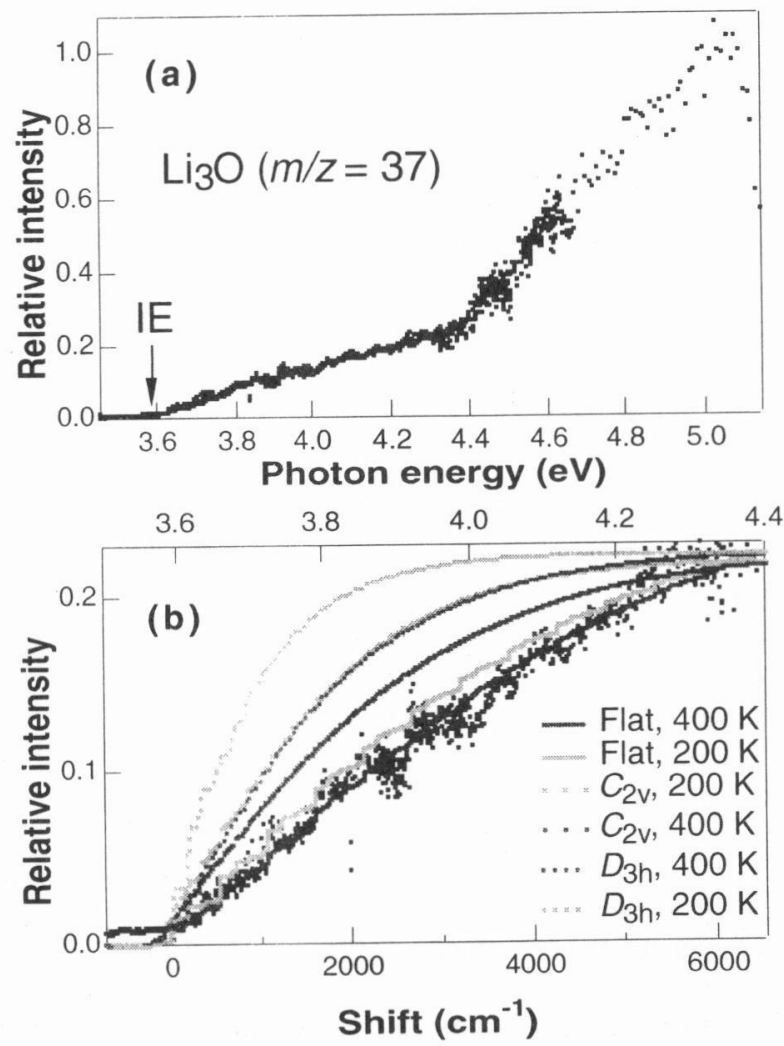

Figure 10. Photoionization efficiency curve measured for $\mathrm{Li}_{3} \mathrm{O}$ (a) and the simulation for the threshold region (b). A good fit was obtained with a flat potential energy surface shown in Figure 12. functional theory (DFT) or ab initio MO theory calculations. The simulated IECs for $\mathrm{Li}_{3} \mathrm{O}$ are superimposed on the experimentally observed IEC in Figure 10(b). The ionization of the $D_{3 \mathrm{~h}}$ structure of neutral $\mathrm{Li}_{3} \mathrm{O}$ does not reproduce well the observed gradual linear rise. Even with parameters for the $C_{2 \mathrm{v}}$ structure, the simulation is far from the observed linear rise of IEC. The well-fitted curve in Figure 10(b) was obtained when two in-plane bending frequencies were adjusted to $10 \mathrm{~cm}^{-1}$ and the molecule is restricted to populate only on the zero-point level in these modes; i.e., no vibrational excitation in these two bending modes. We assumed a flat potential energy surface for the neutral $\mathrm{Li}_{3} \mathrm{O}$ to reproduce the observed curve. ${ }^{53}$ In fact, the $a b$ initio MP2 calculation gives a very flat potential well in the two Li-O-Li bending modes. Figure 12 shows a twodimensional potential energy surface spanned by the two bending coordinates; the horizontal axis for scissoring and the vertical for rocking. We can see a three-fold flat bottom consisting of one $D_{3 \mathrm{~h}}$ minimum and three $C_{2 \mathrm{v}}$ minima in Figure 12(a). A cross sectional view on the horizontal axis shows a double well potential consisting of one of the three $C_{2 \mathrm{v}}$ minima and the $D_{3 \mathrm{~h}}$ minimum [Figure 12 (b)]. The barrier height between the $D_{3 \mathrm{~h}}$ and $C_{2 \mathrm{v}}$ minima is negligibly small $(0.3 \mathrm{~kJ} / \mathrm{mol}$ from the $D_{3 \mathrm{~h}}$ well). Consequently, the vibrational zero-point $(v=0)$ level, which is indicated by the horizontal solid line, lies above the barrier and thus spreads over these two minima. This wide $v=0$ level indicates that the wave function of the vibrational ground state is delocalized over the three $C_{2 \mathrm{v}}$

\section{Neutral}

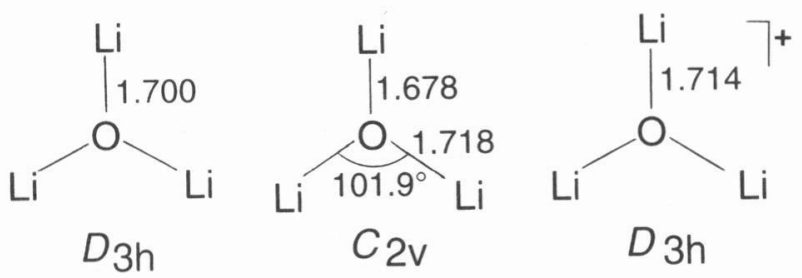

Figure 11. Molecular structures of neutral $\left(D_{3 \mathrm{~h}}, C_{2 \mathrm{v}}\right)$ and cationic $\left(D_{3 \mathrm{~h}}\right) \mathrm{Li}_{3} \mathrm{O}$ calculated at MP2/6-311-G(d) level
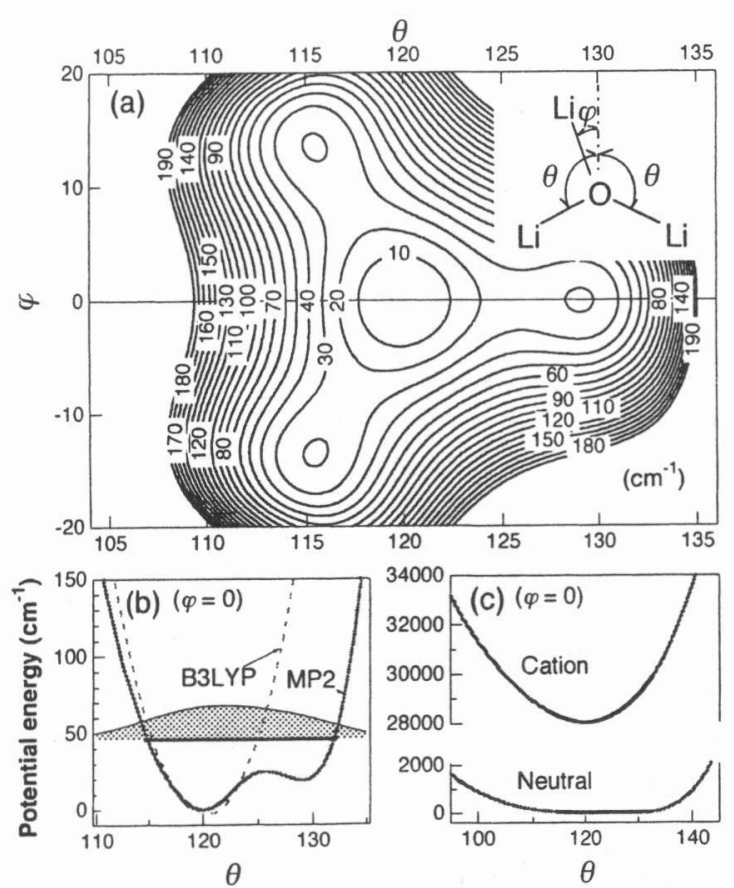

Figure 12. Ab initio potential energy surfaces of $\mathrm{Li}_{3} \mathrm{O}$. (a) The potential well consists of three $C_{2 \mathrm{v}}$ minima and one $D_{3 \mathrm{~h}}$ minimum in the two bending motions. (b) The vibrational ground-state wave function spreads over the saddle points between $D_{3 \mathrm{~h}}$ and $C_{2 \mathrm{v}}$ minima. (c) The vertical ionization from the flat-bottomed potential accesses a wide energy range of the cation. 
minima and the $D_{3 \mathrm{~h}}$ minima. With this large amplitude of vibrational motion, a wide range of cationic potential energy surface is accessible by the vertical ionization from the $v=0$ level as shown in Figure 12(c). Thus the $\mathrm{Li}_{3} \mathrm{O}$ molecule is described as a floppy molecule sharing both the $D_{3 \mathrm{~h}}$ and $\mathrm{C}_{2 \mathrm{v}}$ structures which have nearly the same stability but are different in the localization of the SOMO.

The most significant difference between the $D_{3 \mathrm{~h}}$ and $C_{2 \mathrm{v}}$ structures is the shape or spatial distribution of their SOMO. The shape of SOMO is important characteristics in hyperlithiated molecules. The $D_{3 \mathrm{~h}}$ structure shows fully delocalized SOMO (Figure 13), forming a lithium network comprising all of the three lithium atoms, similar to other hyperlithiated molecules. In contrast, the $C_{2 \mathrm{v}}$ structure has SOMO localized on two lithium atoms to form one $\mathrm{Li}-\mathrm{Li}$ bond and the remaining lithium atom is completely cationic with an natural atomic charge of +0.95 . Therefore, the $C_{2 v}$ structure can be regarded as a salt of $\mathrm{Li}_{2}{ }^{+}$and $\mathrm{LiO}^{-}$. In other words, the $C_{2 \mathrm{v}}$ structure has an electronic structure segregated into a metallic-like $\mathrm{Li}_{2}{ }^{+}$ cation and a $\mathrm{LiO}^{-}$anion. Both the $D_{3 \mathrm{~h}}$ and $C_{2 \mathrm{v}}$ structures have nearly the same stability. Theoretically, the existence of such nearly degenerate isomers with different localization of SOMO in the same irreducible representation was predicted by Schleyer's group for hyperlithiated $\mathrm{Li}_{2} \mathrm{CN}{ }^{54}$ They called the isomers "electronomers." From this point of view, $D_{3 \mathrm{~h}}$ and $C_{2 \mathrm{v}}$ structures of $\mathrm{Li}_{3} \mathrm{O}$ are electronomers, the experimental evidence for which has been provided for the first time. It can be concluded that the $\mathrm{Li}_{3} \mathrm{O}$ molecule is a floppy molecule sharing both the hyperlithiated $D_{3 \mathrm{~h}}$ and segregated $C_{2 \mathrm{v}}$ structures which possess nearly the same stability but are different in the localization of the SOMO.

\section{Conclusion}

In hyperlithiated or hypervalent molecules such as $\mathrm{Li}_{n} \mathrm{~A}$ $\left(\mathrm{Li}_{6} \mathrm{C}, \mathrm{Li}_{3} \mathrm{O}, \mathrm{Li}_{4} \mathrm{O}, \mathrm{Li}_{3} \mathrm{~S}, \mathrm{Li}_{4} \mathrm{~S}, \mathrm{Li}_{4} \mathrm{P}\right), \mathrm{M}_{2} \mathrm{CN}(\mathrm{M}=\mathrm{Li}, \mathrm{Na}, \mathrm{K})$, $\mathrm{Li}_{2} \mathrm{~F}_{n-1}(n=2-4)$, and $\mathrm{Li}_{n}(\mathrm{OH})_{n-1}(n=2-5)$, the excess valence electron is not associated with the electronegative $\mathrm{C}, \mathrm{O}, \mathrm{F}, \mathrm{S}$, and $\mathrm{P}$ atoms as well as $\mathrm{CN}$ and $\mathrm{OH}$ groups, and the electronegative constituent remains content with its normal octet. The excess valence electron delocalizes over lithium atoms contributing to the formation of a lithium network or cage $\left(\mathrm{Li}_{n}{ }^{m+}\right)$ with the $\mathrm{Li}-\mathrm{Li}$ bond, and the hyperlithiated molecules are stabilized by the electrostatic attraction between the cationic $\mathrm{Li}_{n}{ }^{m+}$ and the anionic species (e.g., $\mathrm{C}^{0.9-}, \mathrm{O}^{0.9-}, \mathrm{F}^{1.0-}$, $\left.\mathrm{S}^{1.9-}, \mathrm{CN}^{1.0-}, \mathrm{OH}^{1.0-}\right)$, despite the antibonding character between each of the lithium atom and the electronegative constituent.

Delocalization of the excess valence electron is essential to afford hyperlithiated molecules, and the spatial distribution or shape of SOMO and HOMO, which accommodates the excess valence electron, plays a crucial role in determining the stability of hyperlithiated molecules. In the $\mathrm{Li}_{2} \mathrm{~F}_{n-1}(n=2-4)$

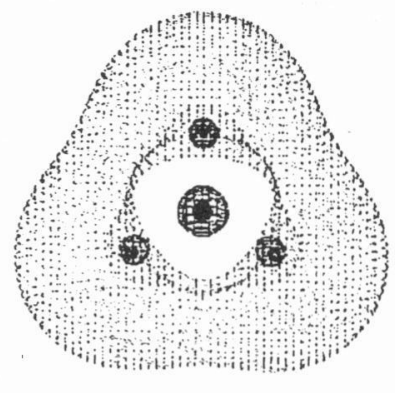

$D_{3 \mathrm{~h}}$

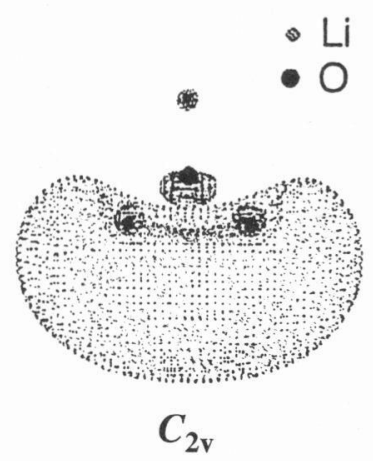

$C_{2 \mathrm{v}}$
Figure 13. Features of $\mathrm{SOMO}$ of $\mathrm{Li}_{3} \mathrm{O}$. The excess valence electron is fully delocalized and forms a lithium cage in the $D_{3 \mathrm{~h}}$ structure, while it is localized and forms a salt consisting of $\mathrm{Li}_{2}^{+}$and $\mathrm{LiO}^{-}$in the $C_{2 \mathrm{v}}$ structure. and $\mathrm{Li}_{n}(\mathrm{OH})_{n-1}(n=2-5)$ systems, SOMO widely spreads over the whole molecule giving a hypelithiated configuration (HLC) at small $n$, but tends to localize around a specific site affording a segregated configuration (SC) with an increase of $n$. Of these Li-rich clusters, IE is relatively high in planar isomers with two terminal lithium atoms $\left(n_{\mathrm{TL}}=2\right)$ reflecting the stability of SOMO.

From the reinvestigation of ionization processes of $\mathrm{Li}_{3} \mathrm{O}$, this hyperlithiated molecule was found to be a floppy molecule sharing both $D_{3 \mathrm{~h}}$ (HLC) and $C_{2 \mathrm{v}}$ (SC) structures which have nearly the same stability but are different in the localization of SOMO. This is the first experimental evidence for electronomers or electronic isomers.

\section{References}

(1) H. Kudo, C. H. Wu, and H. R. Ihle, J. Nucl. Mater. 78, 380 (1978).

(2) C. H. Wu, H. Kudo, and H. R. Ihle, J. Chem. Phys. 70, 1815 (1979).

(3) G. N. Lewis, J. Am. Chem. Soc. 38, 762 (1916).

(4) W. Kossel, Ann. Phys. 49, 229 (1916).

(5) P. v. R. Schleyer, E.-U. Wüthwein, and J. A. Pople, J. Am. Chem. Soc. 104, 5839 (1982).

(6) E. Rehm, A. I. Boldyrev, and P. v. R. Schleyer, Inorg. Chem. 31, 4834 (1992).

(7) H. Kudo, Chem. Lett. 1986, 1611.

(8) C. H. Wu, Chem. Phys. Lett. 139, 357 (1987).

(9) H. Kudo and C. H. Wu, Chem. Express, 5, 633 (1990).

(10) H. Kudo and K. F. Zmbov, Chem. Phys. Lett. 187, 77 (1991).

(11) H. Kudo, Nature 355, 432 (1992).

(12) H. Kudo and C. H. Wu, J. Nucl. Mater. 201, 261 (1993).

(13) H. Kudo, J. Mass Spectrom. Soc. Jpn. 41, 317 (1993).

(14) H. Kudo, K. Yokoyama, and C. H. Wu, J. Chem. Phys. 101, 4190 (1994).

(15) P. v. R. Schleyer, E.-U. Wüthwein, E. Kaufmann, T. Clark, and J. A. Pople, J. Am. Chem. Soc. 105, 5930 (1983).

(16) E.-U. Wüthwein, P. v. R. Schleyer, and J. A. Pople, J. Am. Chem. Soc. 106, 6973 (1984).

(17) P. v. R. Schleyer, in "New Horizons of Quantum Chemistry," ed. by P.-O. Löwdin and B. Pullman, Reidel Publ., Dortrecht (1986), p. 95.

(18) A. E. Reed, R. B. Weinstock, and F. Weinhold, J. Chem. Phys. 83, 735 (1985); J. Am. Chem. Soc. 108, 3586 (1986).

(19) A. E. Reed and F. Weinhold, J. Am. Chem. Soc. 107, 1919 (1985).

(20) J. P. Ritchie and S. M. Bacharach, J. Am. Chem. Soc. 109, 5909 (1987).

(21) C. J. Marsden, J. Chem. Soc., Chem. Commun. 1989, 1356.

(22) J. Ivanic and C. J. Marsden, J. Am. Chem. Soc. 115, 7503 (1993).

(23) J. Ivanic, C. J. Marsden, and D.M. Hassett, J. Chem. Soc., Chem. Commun. 1993, 822.

(24) G. L. Gutsev and A. I. Boldyrev, Chem. Phys. Lett. 92, 262 (1982).

(25) V. G. Zakrewski, W. von Niessen, A. I. Boldyrev, and P. v. R. Schleyer, Chem. Phys. Lett. 197, 195 (1992).

(26) M. Gutovski and J. Simons, J. Phys. Chem. 98, 8326 (1994).

(27)Z. Shi, J. Wang, and R. J. Boyd, J. Phys. Chem. 99, 4941 (1995).

(28) H. Kudo, M. Hashimoto, K. Yokoyama, C. H. Wu, A. E. Dorigo, F. M. Bickelhaupt, and P. v. R. Schleyer, J. Phys. Chem. 99, 6477 (1995).

(29) M. Hashimoto, K. Yokoyama, H. Kudo, C. H. Wu, and P. 
v. R. Schleyer, J. Phys. Chem. 100, 15770 (1996).

(30) H. Kudo, M. Hashimoto, K. Yokoyama, C. H. Wu, and P. v. R. Schleyer, Thermochim. Acta 299, 113 (1997).

(31) H. Kudo and K. Yokoyama, Bull. Chem. Soc. Jpn. 69, 1459 (1996).

(32) H. Kudo, M. Hashimoto, H. Tanaka, and K. Yokoyama, J. Mass Spectrom. Soc. Jpn. 47, 2 (1999).

(33) K. Yokoyama, N. Haketa, M. Hashimoto, K. Furukawa, H. Tanaka, and H. Kudo, Chem. Phys. Lett. 320, 645 (2000).

(34) K. Yokoyama, N. Haketa, H. Tanaka, and H. Kudo, Chem. Phys. Lett. 330, 339 (2000).

(35) H. Tanaka, K. Yokoyama, and H. Kudo, J. Chem. Phys. 113, 1821 (2000).

(36) H. Tanaka, K. Yokoyama, and H. Kudo, J. Chem. Phys. 114, 152 (2001).

(37) U. Landman, D. Sharf, and J. Jortner, Phys. Rev. Lett. 54, 1860 (1985).

(38) B. Vezin, Ph. Dugourd, D. Rayane, P. Labastie, J. Chevaleyre, and M. Broyer, Chem. Phys. Lett. 206, 521 (1993).

(39) V. Bonacic-Koutecký, J. Gaus, M. F. Guest, L. Češpiva, and J. Koutecký, Chem. Phys. Lett. 206, 528 (1993).

(40) P. Lievens, P. Thoen, S. Bouckaert, W. Bouwen, F. Vanhoutte, H. Weidele, R. E. Silverans, A. N.-Vázquez, and P. v. R. Schleyer, J. Chem. Phys. 110, 10316 (1999).

(41) P. Lievens, P. Thoen, S. Bouckaert, W. Bouwen, F.
Vanhoutte, H. Weidele, and R. E. Silverans, Chem. Phys. Lett. 302, 571 (1999).

(42) R. Antoine, Ph. Dugourd, D. Rayane, E. Benichou, and M. Broyer, J. Chem. Phys. 107, 2264 (1997).

(43) R. Antoine, Ph. Dugourd, D. Rayane, and M. Broyer, J. Chem. Phys. 104, 110 (1996).

(44) H. G. Limberger and T. P. Martin, J. Chem. Phys. 90, 2979 (1989).

(45) P. Labasite, J.-M. L'Hermite, Ph. Poncharal, and M. Sence, J. Chem. Phys. 103, 6362 (1995).

(46) E. C. Honea, M. L. Homer, and R. L. Whetten, Phys. Rev. B 47, 7480 (1993).

(47) G. Rajagopal, R. N. Barnett, and U. Landman, Phys. Rev. Lett. 67, 727 (1991).

(48) A. W. Castleman Jr. and K. H. Bowen Jr., J. Phys. Chem. 100, 12911 (1996).

(49) G. Durand, J. Giraud-Girard, D. Maynau, F. Spiegelmann, and F. Calvo, J. Chem. Phys. 110, 7871 (1999).

(50) R. L. Whetten, Acc. Chem. Res. 26, 49 (1993).

(51) A. E. Reed, L. A. Curtiss, and F. Weinhold, Chem. Rev. 88, 899 (1985).

(52) G. L. Gutsev and A. I. Boldyrev, Chem. Phys. Lett. 92, 262 (1982).

(53) K. Yokoyama, H. Tanaka, and H. Kudo, J. Phys. Chem. A 105, 4312 (2001).

(54) A. Dorigo and P. v. R. Schleyer, Chem. Phys. Lett. 186, 363 (1991). 